\title{
El acceso a los medios de transporte aéreo por las personas con discapacidad orgánica: el caso de la diálisis peritoneal automatizada de las personas con enfermedad renal crónica
}

\author{
Access to air transportation by people with organic disabilities: The case \\ of automated peritoneal dialysis of people with chronic kidney disease
}

\begin{abstract}
Resumen
El objetivo del trabajo es analizar la libertad de desplazamiento y circulación reconocida a las personas con discapacidad, que es clave para construir una 'ciudadanía móvil' que permita su inclusión social enfrentándose a las desventajas de movilidad en el transporte. El ejercicio de esta libertad debe garantizarse con medidas de diseño universal y, en caso de necesidad, con ajustes razonables que no supongan una carga desproporcionada. El principal resultado es mostrar que, en España, las personas con enfermedad renal crónica que realizan la diálisis peritoneal automatizada se encuentran con una serie de barreras que impiden el disfrute de la libertad de desplazamiento y circulación en igualdad de condiciones que el resto de las personas con discapacidad que requieren el uso de equipos de movilidad. El valor añadido de este trabajo radica en que plantea una nueva faceta de la accesibilidad universal, del derecho a la movilidad, compatible con la seguridad y del enfoque de los ajustes razonables.
\end{abstract}

\section{Palabras clave}

Discapacidad, derechos, discriminación, libertad de desplazamiento y circulación, ciudadanía móvil, desventaja en el transporte, enfermedad renal crónica, diálisis peritoneal automatizada.

\section{Abstract}

This work studies the freedom of movement and circulation recognized to people with disabilities, which is key to building a 'mobile citizenship' that allows their social inclusion, facing the disadvantages of mobility in transport. The exercise of this freedom must be guaranteed with measures of universal design and, if necessary, with reasonable adjustments that do not imply a disproportionate burden. The main outcome is to show that, in Spain, people with chronic kidney disease who perform automated peritoneal dialysis face a set of barriers that prevent the enjoyment of freedom of movement and circulation on equal terms with other people with disabilities requiring the use of mobility equipment. The added value of this work lies in the fact that it raises a new face of universal accessibility, the right to mobility, compatible with the security and reasonable accommodation approach.
\end{abstract}

\section{Keywords}

Disability, rights, discrimination, liberty of movement, mobile citizenship, disadvantage in transportation, chronic kidney disease, automated peritoneal dialysis.

\author{
Miguel Ángel Ramiro Avilés \\ <miguelangel.ramiro@uah.es>
}

Universidad de Alcalá. España

Paulina Ramírez Carvajal <paulina.ramirez@uah.es>

Universidad de Alcalá. España

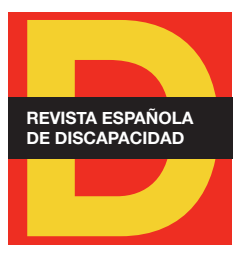

Para citar:

Ramiro, M. A. y Ramírez, P. (2021). El acceso a los medios de transporte aéreo por las personas con discapacidad orgánica: el caso de la diálisis peritoneal automatizada de las personas con enfermedad renal crónica. Revista Española de Discapacidad, 9(1), pp. 179-195.

Doi: <https://doi.org/10.5569/23405104.09.01.09>

Fecha de recepción: 16-05-2020 Fecha de aceptación: 01-06-2021 


\section{Introducción ${ }^{1}$}

En este trabajo se analiza el ejercicio de la libertad de desplazamiento y circulación por las personas con enfermedad renal crónica que realizan su tratamiento renal sustitutorio mediante la diálisis peritoneal automática ${ }^{2}$, para la cual necesitan utilizar una cicladora ${ }^{3}$, cuando viajan en avión. Las personas con enfermedad renal crónica que realizan la diálisis peritoneal automática pueden encontrarse con situaciones en las que el personal encargado de la seguridad del vuelo, primero, impida la facturación de la cicladora alegando que no puede ser transportada por contener una batería de litio; segundo, advierta que la cicladora no puede llevarse como equipaje de mano en la cabina del avión porque entre sus componentes hay una batería de litio y debe facturarse para ser transportada en la bodega del avión; o, tercero, solicite la compra de un título de transporte adicional para que la cicladora ocupe el asiento contiguo.

Estas situaciones requieren que se analice si las personas con enfermedad renal crónica que realizan su tratamiento renal sustitutorio mediante diálisis peritoneal automática tienen derecho a que, dadas las condiciones de accesibilidad universal en el transporte aéreo, se realice un ajuste razonable para que la cicladora pueda ser embarcada como un equipo de movilidad en la cabina del avión, pues no es un objeto que ponga en peligro la seguridad de la aeronave; o si, por el contrario, están justificadas tanto la denegación del embarque por transportar la cicladora como equipaje de mano cuanto la obligación de facturar la cicladora para que sea transportada en la bodega del avión o la compra de un segundo billete para que la cicladora viaje en el asiento contiguo. En general, la diálisis peritoneal automática se realiza por personas con enfermedad renal crónica que precisan mayor flexibilidad en su tratamiento acorde a sus necesidades sociales y valores individuales, pero también está especialmente indicada, entre otras, para las personas en edad pediátrica y de edad avanzada (Vega-Díaz, 2011).

\footnotetext{
1. Este trabajo es uno de los resultados del proyecto de investigación 'Discapacidad, enfermedad crónica y accesibilidad a los derechos', financiado por el Ministerio de Ciencia, Universidades e Innovación (DER2016- 80138-R).

2. Los riñones son los órganos que depuran la sangre de sustancias que pueden ser tóxicas para el organismo. En las enfermedades renales se irá produciendo una disminución significativa y progresiva del trabajo de limpieza hasta llegar a ser insuficiente. Debido a esto, en la sangre se irán acumulando sustancias tóxicas para el organismo que no son eliminadas por la orina. El resultado de esa acumulación será peligroso para la vida, pudiendo causar el fallecimiento de la persona. Todos los objetivos terapéuticos están dirigidos, en primer lugar, a disminuir y tratar las complicaciones asociadas tanto a la insuficiencia renal (en su fase aguda y crónica) como a la enfermedad renal terminal y, en segundo lugar, a preparar con suficiente antelación el tratamiento sustitutivo de la función renal, como pueden ser la diálisis o el trasplante de riñón. La diálisis es la terapia de reemplazo más utilizada en estos casos y supone - explicado de forma muy básica- que una máquina, también llamada riñón artificial, se encarga de limpiar y depurar la sangre del organismo. Es un tratamiento del que dependen absolutamente quienes tienen una enfermedad renal crónica en fase terminal. Esta calificación depende del nivel de filtrado glomerular. El filtrado glomerular tiene diferentes estadios. El estadio 5 es cuando se necesita la diálisis para sobrevivir, pues el filtrado glomerular es inferior a $15 \mathrm{ml} / \mathrm{min}$ (Subdirección General de Calidad y Cohesión, 2015). La diálisis limpia la sangre de substancias retenidas. Esta limpieza puede hacerse de dos formas: la hemodiálisis o la diálisis peritoneal. La única manera de que estas personas dejen de dializarse sería haciéndose un trasplante renal. Sin embargo, no todas las personas son candidatas para recibir un trasplante o deben esperar un tiempo hasta que llega un órgano compatible, ya sea de donante vivo o de donante fallecido. Solo un $20 \%$ de las personas que necesitan diálisis es apto para el trasplante. Se calcula que en España son 57.000 las personas que están incluidas en programas de hemodiálisis periódica (Sociedad Española de Nefrología, 2018). El acceso a ambas modalidades de diálisis está garantizado porque forman parte de la cartera de servicios especializados del Sistema Nacional de Salud.

3. Una cicladora es la máquina que permite hacer la diálisis peritoneal automática sin necesidad de acudir a un servicio de nefrología en un hospital o centro especializado. La diálisis se consigue mediante la introducción de un líquido en la cavidad peritoneal, situada en el abdomen, a través de un catéter de plástico. La depuración de la sangre se logra gracias a que el peritoneo es una membrana que hace la función de filtro. Este método de diálisis permitiría que las personas con enfermedad renal crónica lleven una vida lo más normalizada posible, accediendo a los mismos lugares, ámbitos, bienes y servicios que están a disposición de cualquier otra persona, desplazándose o viajando libremente ya que la diálisis se puede realizar en cualquier sitio que reúna unas mínimas condiciones higiénicas. La diálisis peritoneal automática permite, por ejemplo, que la persona con enfermedad renal crónica mantenga una actividad laboral normalizada ya que puede dializarse por la noche durante 8-9 horas. Según la Federación Nacional de Alcer, en España, cerca de 3.400 personas dependen de la diálisis domiciliaria, algo más de 3.100, de tipo peritoneal y unos 200, de hemodiálisis, de los que unos 1.500 utilizan cicladoras.
} 


\section{Metodología}

Se parte de la base empírica que proporcionan las consultas recibidas en la Clínica Legal organizada conjuntamente por Alcer y la Universidad de Alcalá en 2019. En esas consultas, a personas con enfermedad renal crónica que hacen diálisis peritoneal automática y que tienen reconocido un grado de discapacidad superior al $33 \%$, se les denegaba el embarque en aviones de líneas aéreas comerciales porque se consideraba que la pila de litio de la cicladora era un problema para la seguridad del avión; se les exigía que la cicladora fuese facturada para ser transportada en la bodega de carga; o se les invitaba a comprar un segundo billete para que la cicladora viajase en el asiento contiguo, aduciéndose que no había espacio en la cabina de pasajeros. La elaboración de las respuestas pasó por el análisis de los instrumentos normativos que regulaban el derecho de las personas con discapacidad a la libertad de desplazamiento y circulación, con la finalidad de saber si se estaba produciendo un trato discriminatorio hacia este grupo de personas con discapacidad.

Cabe destacar el análisis de la Convención sobre los Derechos de las Personas con Discapacidad (en adelante, la Convención), así como diversas observaciones generales del Comité de Naciones Unidas sobre los Derechos de las Personas con Discapacidad; el Pacto Internacional de Derechos Civiles y Políticos y el Comentario General 27; la Constitución Española, la Carta de los Derechos Fundamentales de la Unión Europea y otras normas jurídicas de menor rango; así como las jurisprudencias del Tribunal Constitucional, del Tribunal de Justicia de la Unión Europea y del Tribunal Europeo de Derechos Humanos. De igual forma se consultó bibliografía científica secundaria relevante sobre los derechos de las personas con discapacidad, en especial a la accesibilidad universal y a los ajustes razonables; el concepto de ciudadanía móvil; y el derecho a la libertad de desplazamiento y circulación de las personas por España y la Unión Europea.

\section{Resultados}

\section{1. ¿Quién es persona con discapacidad?}

La primera cuestión que debe analizarse es a quién se reconoce legalmente en España la condición de 'persona con discapacidad'. Dado que España ha firmado y ratificado la Convención, el artículo 96 de la Constitución Española la incluye como parte del ordenamiento interno y el artículo 10.2 de la Constitución Española la señala como un criterio interpretativo de los derechos fundamentales y libertades reconocidas en la Constitución.

El artículo 1 de la Convención y el apartado 1 del artículo 4 del Real Decreto Legislativo 1/2013, por el que se aprueba el texto refundido de la Ley general de derechos de las personas con discapacidad y de su inclusión social definen como 'persona con discapacidad' «a aquellas que tengan deficiencias físicas, mentales, intelectuales o sensoriales a largo plazo que, al interactuar con diversas barreras, puedan impedir su participación plena y efectiva en la sociedad, en igualdad de condiciones con las demás». Como se afirma en la exposición de motivos de la Ley general de derechos de las personas con discapacidad y de su 
inclusión social, con ella se ha pretendido recoger el modelo de la discapacidad basado en derechos por el que aboga la Convención, que propone un concepto de 'persona con discapacidad' amplio. No obstante, el artículo 4 en su apartado 2 condiciona dicho reconocimiento a que «además de lo establecido en el apartado anterior, y a todos los efectos, tendrán la consideración de personas con discapacidad aquellas a quienes se les haya reconocido un grado de discapacidad igual o superior al 33 por ciento (...)».

La aplicación a las personas con enfermedad renal crónica que realizan diálisis peritoneal automática de los baremos incluidos en el Real Decreto 1971/1999, de 23 de diciembre, de procedimiento para el reconocimiento, declaración y calificación del grado de discapacidad (en adelante, RD 1971/1999), permitiría la obtención de un grado de discapacidad igual o superior al 33 por ciento. Como señala el artículo 4 del RD 1971/1999, el grado de discapacidad se obtiene aplicando unos criterios técnicos unificados, valorándose tanto las discapacidades que presente la persona como los factores sociales complementarios. En el artículo 5 se aclara que estos factores sociales nunca podrán sobrepasar los 15 puntos y solo se aplicarán cuando la valoración de la discapacidad haya alcanzado un grado igual o superior al 25 por ciento. El capítulo 8 del anexo $1 \mathrm{~A}$ recoge las normas generales para la evaluación de las deficiencias del riñón y los criterios para la asignación del porcentaje de discapacidad originado.

Los criterios para la asignación del porcentaje de discapacidad atribuible a deficiencias del riñón van desde la clase 1 , a la que corresponde el $0 \%$, al ser personas que tienen insuficiencia renal crónica con aclaramientos de creatinina superiores a $50 \mathrm{ml} / \mathrm{min}$ o presentan episodios recurrentes de afectación renal transitoria que precisan atención médica documentada menos de tres veces o durante menos de 30 días al año; la clase 2, a la que corresponde entre el 1 y el $24 \%$, al ser personas que tienen insuficiencia renal crónica con aclaramientos de creatinina entre 20 y $50 \mathrm{ml} / \mathrm{min}$ o presentan episodios recurrentes de afectación renal transitoria que precisan atención médica documentada más de tres veces o más de 30 días al año; la clase 3 , a la que corresponde entre el 25 y el $49 \%$, al ser personas con insuficiencia renal crónica con aclaramientos de creatinina inferiores a $20 \mathrm{ml} / \mathrm{min}$, no precisando tratamiento dialítico continuado y con un grado de discapacidad leve o moderado, o personas que presentan un deterioro progresivo de la función renal en el último año, con aclaramientos de creatinina entre 20 y $50 \mathrm{ml} / \mathrm{min}$ y su grado de discapacidad es leve o moderado; la clase 4, a la que corresponde entre el 50 y el $70 \%$, al ser personas que tienen insuficiencia renal crónica que precisan tratamiento dialítico continuado o con un grado de discapacidad grave estando contraindicado el tratamiento sustitutorio; y la clase 5, a la que corresponde un $75 \%$, al ser personas que presentan patología renal, que cumplen los parámetros objetivos de la clase 4 y su grado de discapacidad es muy grave, dependiendo de otra persona para realizar las actividades de autocuidado.

En el capítulo 1 del anexo $1 \mathrm{~A}$ se señala que las actividades de autocuidado son aquellas que afectan al vestirse, comer, evitar riesgos, aseo e higiene personal, y que los grados de la discapacidad van desde el grado 1 (discapacidad nula), cuando los síntomas, signos o secuelas, de existir, son mínimos y no justifican una disminución de la capacidad de la persona para realizar las actividades de la vida diaria; grado 2 (discapacidad leve), cuando los síntomas, signos o secuelas existen y justifican alguna dificultad para llevar a cabo las actividades de la vida diaria, pero son compatibles con la práctica totalidad de las mismas; grado 3 (discapacidad moderada), cuando los síntomas, signos o secuelas causan una disminución importante o imposibilidad de la capacidad de la persona para realizar algunas de las actividades de la vida diaria, siendo independiente en las actividades de autocuidado; grado 4 (discapacidad grave), cuando los síntomas, signos o secuelas causan una disminución importante o imposibilidad de la capacidad de la persona para realizar la mayoría de las actividades de la vida diaria, pudiendo estar afectada alguna de las actividades 
de autocuidado; grado 5 (discapacidad muy grave), cuando los síntomas, signos o secuelas imposibilitan la realización de las actividades de la vida diaria.

Atendiendo a este criterio normativo, a las personas que realizan la diálisis peritoneal automática se les debería encuadrar en la clase 4, correspondiéndoles entre el $50 \%$ y el $70 \%$ de discapacidad, por tener una insuficiencia renal crónica que precisa tratamiento dialítico continuado, a pesar de que el grado oscilaría entre el 1 y el 2 .

No obstante, dado que habrá que aplicar el Reglamento Europeo 1107/2006, del Parlamento Europeo y del Consejo, de 5 de julio, sobre derechos de las personas con discapacidad o movilidad reducida en el transporte aéreo (en adelante, Reglamento Europeo 1107/2006), es también interesante subrayar que, según la jurisprudencia del Tribunal de Justicia de la Unión Europea, aunque estas personas con enfermedad renal crónica que realizan la diálisis peritoneal automática mediante una cicladora no tuvieran reconocido administrativamente el grado de discapacidad, también podrían ser consideradas como personas con discapacidad, pues en las sentencias Ring y Daouidi se amplía este concepto hasta abarcar a las personas con una enfermedad crónica.

La sentencia del Tribunal de Justicia de la Unión Europea, de 11 de abril de 2013 (asunto C-335/11), conocida como caso Ring, señala que en el concepto de personas con discapacidad debe incluirse a las personas con una enfermedad crónica. En el fallo se estableció que «el concepto de 'discapacidad' (...) debe interpretarse en el sentido de que comprende una condición causada por una enfermedad diagnosticada médicamente como curable o incurable, cuando esta enfermedad acarrea una limitación, derivada en particular de dolencias físicas, mentales o psíquicas que, al interactuar con diversas barreras, puede impedir la participación plena y efectiva de la persona de que se trate en la vida profesional en igualdad de condiciones con los demás trabajadores, y si esta limitación es de larga duración». Este fallo ha sido confirmado por el Tribunal de Justicia de la Unión Europea en la sentencia de 18 diciembre de 2014 (asunto C-354/13), conocida como caso Daouidi, al señalar que «(...) el concepto de 'discapacidad' debe entenderse como referido a una limitación, derivada en particular de dolencias físicas, mentales o psíquicas, a largo plazo, que, al interactuar con diversas barreras, puede impedir la participación plena y efectiva de la persona de que se trate en la vida profesional en igualdad de condiciones con los demás trabajadores (...). Dicho concepto de 'discapacidad' debe entenderse en el sentido de que no solo abarca la imposibilidad de ejercer una actividad profesional, sino también una dificultad para el ejercicio de esta».

\subsection{El disfrute a la libertad de desplazamiento y circulación en igualdad de condiciones por las} personas con discapacidad: medidas de accesibilidad universal, ajustes razonables y proporcionalidad de las cargas

Un caso como el que estamos analizando afecta al disfrute de la libertad de desplazamiento y de circulación que las personas con discapacidad tienen reconocida en el artículo 18 de la Convención, en el artículo 12 del Pacto Internacional de Derechos Civiles y Políticos, en el artículo 19 de la Constitución Española y en el artículo 45 de la Carta de los Derechos Fundamentales de la Unión Europea. Esta libertad, que les permite entrar y salir libremente del territorio nacional y de la Unión Europea ${ }^{4}$ debe garantizarse, según lo

4. España. Tribunal Constitucional. Sentencia 72/2005, 4 de abril de 2005. Fundamento Jurídico 5. Boletín Oficial del Estado, 10 de mayo de 2005, núm. 111, pp. 17-23. 
establecido en los artículos 5 y 22 de la Ley general de derechos de las personas con discapacidad y de su inclusión social, adoptando las medidas pertinentes de accesibilidad universal, igualdad de oportunidades y no discriminación, entre las que se encuentran los ajustes razonables, para que las personas con discapacidad puedan disfrutar de su derecho a vivir de forma independiente y a participar plenamente en todos los aspectos de la vida.

El Comité de Naciones Unidas sobre los Derechos de las Personas con Discapacidad (en adelante, el Comité) ha señalado que el disfrute de la libertad de movimiento por parte de las personas con discapacidad para que puedan vivir de forma independiente, participar plenamente en la sociedad en igualdad de condiciones, desarrollando de esa manera la identidad y la personalidad de cada individuo, implica el acceso al transporte. Las personas con discapacidad, sostiene el Comité, deben contar «con todos los medios necesarios para que puedan tomar opciones y ejercer control sobre sus vidas, y adoptar todas las decisiones que las afecten. La autonomía personal y la libre determinación son fundamentales para la vida independiente, [incluido] el acceso al transporte (...)" (Comité sobre los Derechos de las Personas con Discapacidad, 2017, p. 4). Y afirma que «sin acceso al entorno físico, el transporte, la información y las comunicaciones, incluidos los sistemas y las tecnologías de la información y las comunicaciones, y a otros servicios e instalaciones abiertos al público o de uso público, las personas con discapacidad no tendrían iguales oportunidades de participar en sus respectivas sociedades» (Comité sobre los Derechos de las Personas con Discapacidad, 2014, p. 1).

La garantía del acceso al transporte exige adoptar tanto medidas de accesibilidad universal, que son medidas ex ante aplicadas a grupos de personas, como medidas de ajuste razonable, que son medidas ex nunc aplicadas a casos individuales (Comité sobre los Derechos de las Personas con Discapacidad, 2018, p. 7). En ambos casos se estaría logrando, como señala el Comité, una mayor profundidad del principio de igualdad mediante la transformación de un concepto de igualdad formal por uno de igualdad material: «la igualdad de oportunidades, como principio general de la Convención en virtud del artículo 3 , constituye un paso importante en la transición de un modelo de igualdad formal a un modelo de igualdad sustantiva. La igualdad formal lucha contra la discriminación directa tratando de manera similar a las personas que están en situación similar. Puede ayudar a combatir los estereotipos negativos y los prejuicios, pero no puede ofrecer soluciones al 'dilema de la diferencia', ya que no tiene en cuenta ni acepta las diferencias entre los seres humanos. La igualdad sustantiva, en cambio, aborda también la discriminación indirecta y estructural, y tiene en cuenta las relaciones de poder. Admite que el 'dilema de la diferencia' entraña tanto ignorar las diferencias entre los seres humanos como reconocerlas, a fin de lograr la igualdad” (Comité sobre los Derechos de las Personas con Discapacidad, 2018, p. 3).

Aunque la discapacidad no está expresamente incluida en el listado de factores diferenciadores del artículo 14 de la Constitución Española, el Tribunal Constitucional ha declarado en diversas ocasiones que ese elenco no está cerrado y ha admitido la discapacidad como una causa real de discriminación ${ }^{5}$. A eso añade que «las medidas que se instrumentan para procurar la igualdad de oportunidades y la integración social y profesional de las personas con discapacidad, incluyendo aquellas de acción positiva, tienen una estrecha conexión (...) con el mandato contenido en el artículo 9.2 Constitución Española»6. Esto supone, en primer lugar, que el principio de igualdad no postule ni como fin ni como medio la paridad y solo exija la razona-

5. España. Tribunal Constitucional. Sentencia 3/2018, de 22 de enero de 2018. Fundamento Jurídico 5. Boletín Oficial del Estado, 21 de febrero de 2008, núm. 46, pp. 20410-20432.

6. España. Tribunal Constitucional. Sentencia 269/1994, de 3 de octubre de 1994. Fundamento Jurídico 4. Boletín Oficial del Estado, 8 de noviembre de 1994, núm. 267, pp. 43-48. 
bilidad de la diferencia de trato; y, en segundo lugar, que mientras que las prohibiciones de discriminación imponen como fin y como medio la parificación de trato legal, el legislador solo puede utilizarlas excepcionalmente como criterio de diferenciación jurídica ${ }^{7}$. Se busca, en definitiva, una igualdad inclusiva para que las personas con discapacidad afronten las desventajas socioeconómicas; combatan el estigma, los estereotipos, los prejuicios y la violencia; y reafirmen su condición de miembros de una sociedad que debe ser diversa (Comité sobre los Derechos de las Personas con Discapacidad, 2018, p. 3).

Las medidas de accesibilidad universal se enfrentarían a las barreras desde la raíz del problema pues es «una condición previa esencial para que las personas con discapacidad disfruten de manera efectiva y en condiciones de igualdad de los derechos» (Comité sobre los Derechos de las Personas con Discapacidad, 2014 , p. 2). Las medidas de accesibilidad universal obligan a «proporcionar accesibilidad antes de recibir una petición individual para entrar en un lugar o utilizar un servicio» (Comité sobre los Derechos de las Personas con Discapacidad, 2014, p. 8). Al ser una obligación ex ante, «la accesibilidad debe integrarse en los sistemas y procesos sin importar la necesidad de una persona con discapacidad concreta» (Comité sobre los Derechos de las Personas con Discapacidad, 2018, p. 7). Como señala el Comité, «la accesibilidad debe considerarse una reafirmación, desde el punto de vista específico de la discapacidad, del aspecto social del derecho al acceso. La Convención sobre los derechos de las personas con discapacidad incluye la accesibilidad como uno de sus principios fundamentales, una condición previa esencial para que las personas con discapacidad disfruten de manera efectiva y en condiciones de igualdad de derechos" (Comité sobre los Derechos de las Personas con Discapacidad, 2014, p. 2).

En la Convención, el artículo 9 establece que «a fin de que las personas con discapacidad puedan vivir en forma independiente y participar plenamente en todos los aspectos de la vida, los Estados Partes adoptarán medidas pertinentes para asegurar el acceso de las personas con discapacidad, en igualdad de condiciones con las demás, al entorno físico, el transporte (...)”. Este artículo reconoce a las personas con discapacidad el derecho de acceso en igualdad de condiciones a bienes, productos y servicios abiertos al público o de uso público, independientemente de que la entidad sea pública o privada, consagrándose «la accesibilidad como la condición previa para que las personas con discapacidad puedan vivir en forma independiente, participar plenamente y en pie de igualdad en la sociedad y disfrutar de manera irrestricta de todos sus derechos humanos y libertades fundamentales en igualdad de condiciones con los demás» (Comité sobre los Derechos de las Personas con Discapacidad, 2014, p. 5).

La accesibilidad debe abordarse en toda su complejidad pues afecta al ejercicio de todos los derechos por todas las personas. Como afirma el Comité, «en la medida en que los bienes, productos y servicios están abiertos al público o son de uso público, deben ser accesibles a todas las personas, independientemente de que la entidad que los posea u ofrezca sea una autoridad pública o una empresa privada. Las personas con discapacidad deben tener igualdad de acceso a todos los bienes, productos y servicios abiertos al público o de uso público, de manera que garantice su acceso efectivo y en condiciones de igualdad que respete su dignidad. Este enfoque se basa en la prohibición de la discriminación; la denegación de acceso debe considerarse un acto discriminatorio, independientemente de que quien lo cometa sea una entidad pública o privada» (Comité sobre los Derechos de las Personas con Discapacidad, 2014, p. 5).

7. España. Tribunal Constitucional. Sentencia 3/2018, de 22 de enero de 2018. Fundamento Jurídico 4. Boletín Oficial del Estado, 21 de febrero de 2018, núm. 46, pp. 20410-20432. 
Una vez que se hayan implementado, o intentado implementar, las medidas de accesibilidad universal, proporcionando los apoyos que fuesen necesarios, no obteniéndose el resultado esperado, será el turno de las medidas que buscan adoptar ajustes razonables, que también tendrían como objetivo proporcionar acceso a las personas con discapacidad al ejercicio de sus derechos en igualdad de condiciones con las demás personas. Como ha señalado el Tribunal Europeo de Derechos Humanos en el caso Çam contra Turquía, los Estados tienen la obligación de adoptar los ajustes razonables que sean necesarios para evitar la discriminación ${ }^{8}$. En ese sentido, tal y como se dispone en el artículo 63 de la Ley general de derechos de las personas con discapacidad y de su inclusión social, se produciría una vulneración del derecho a la igualdad de oportunidades cuando, por motivo de o por razón de discapacidad no se realizan los ajustes razonables. Igualmente se pronuncia el artículo 2 de la Convención cuando señala que constituye una discriminación la denegación de las modificaciones o adaptaciones necesarias y adecuadas (que no impongan una carga desproporcionada o indebida) cuando se requieran para garantizar el goce o ejercicio, en igualdad de condiciones, de derechos o libertades.

Al ser una obligación ex nunc, «los ajustes razonables deben realizarse desde el momento en que una persona con discapacidad requiera acceder a situaciones o entornos no accesibles, o quiera ejercer sus derechos» (Comité sobre los Derechos de las Personas con Discapacidad, 2018, p. 7). No obstante, «los Estados partes tienen la obligación de proporcionar accesibilidad antes de recibir una petición individual para entrar en un lugar o utilizar un servicio (...). En el caso de las personas con deficiencias raras que no se tuvieron en cuenta al elaborar las normas de accesibilidad (...) la aplicación de las normas de accesibilidad puede ser insuficiente para garantizarles el acceso. En tales casos, pueden aplicarse ajustes razonables (...)» (Comité sobre los Derechos de las Personas con Discapacidad, 2014, p. 8).

Como ya se ha indicado, los ajustes razonables «son exigibles desde el momento en que una persona con una deficiencia los necesita en una determinada situación (...). Los ajustes razonables pueden utilizarse como medio para garantizar la accesibilidad a una persona con una discapacidad en una situación particular. Con la introducción de ajustes razonables se pretende hacer justicia individual en el sentido de garantizar la no discriminación o la igualdad, teniendo en cuenta la dignidad, la autonomía y las elecciones de la persona» (Comité sobre los Derechos de las Personas con Discapacidad, 2014, p. 9).

Los ajustes razonables se solicitan o negocian entre la persona que requiere el acceso y la persona facultada para hacerlos, pues, por lo general, solo benefician a quienes los solicitan. Como explica el Comité, «la obligación de realizar ajustes razonables es una obligación reactiva individualizada, que debe atenderse desde el momento en que se recibe una solicitud de ajustes. Los ajustes razonables exigen que el garante de los derechos entable un diálogo con la persona con discapacidad" (Comité sobre los Derechos de las Personas con Discapacidad, 2018, p. 7). Por lo tanto, la obligación de realizar ajustes razonables implicaría, en primer lugar, dialogar con la persona con discapacidad una vez que se han detectado los obstáculos que afectan negativamente al acceso a los derechos; en segundo lugar, evaluar si el ajuste solicitado es factible realizarlo técnicamente; en tercer lugar, si el ajuste es necesario, adecuado y eficaz para garantizar el ejercicio del derecho; en cuarto lugar, si impone una carga desproporcionada o indebida; en quinto y último lugar, ejecutar las modificaciones o adaptaciones.

8. Consejo de Europa. Sentencia del Tribunal Europeo de Derechos Humanos. Caso Çam contra Turquía, n. 51500/08, 23 de febrero de 2016, pp. 65 y 69. 
A diferencia de las medidas de accesibilidad universal, los ajustes razonables se refieren a casos individuales y la entidad pública o privada concernida puede alegar que representan una carga indebida (Comité sobre los Derechos de las Personas con Discapacidad, 2014, pp. 8-9). Así, mientras la obligación de establecer la accesibilidad es incondicional, la obligación de establecer ajustes razonables está condicionada. Como explica el Comité, es preciso diferenciar entre 'razonabilidad de la medida' y 'carga desproporcionada'. En primer lugar, la razonabilidad de los ajustes hace referencia a la pertinencia, idoneidad y eficacia para lograr que la persona con discapacidad pueda disfrutar de su derecho. Una vez determinada la razonabilidad se establecerá si constituye o no una carga desproporcionada, que es el verdadero límite en la realización de los ajustes pues pueden denegarse, aunque sean razonables. En ese sentido, la Ley general de derechos de las personas con discapacidad y de su inclusión social señala, en su artículo 66.2, que para determinar si un ajuste es razonable "se tendrán en cuenta los costes de la medida, los efectos discriminatorios que suponga para las personas con discapacidad su no adopción, la estructura y características de la persona, entidad u organización que ha de ponerla en práctica y la posibilidad que tenga de obtener financiación oficial o cualquier otra ayuda». No obstante, como ha señalado el Tribunal Constitucional, una vez que se hayan explicado convenientemente los motivos, mediante informes técnicos, por los que se ha seguido una opción que afecta a un derecho fundamental sustantivo, mediante un razonamiento que supere el juicio de proporcionalidad y sea coherente con la finalidad principal que se pretende, se podrá disponer la denegación del ajuste sin necesidad de ponderar si es o no una carga desproporcionada9 .

En el caso de la diálisis peritoneal automática no estamos ante un problema de accesibilidad universal pues el Reglamento Europeo 1107/2006 trata de crear las condiciones para que en los aeropuertos de la Unión Europea pueda ejercerse el derecho de acceso. Por el contrario, estamos ante la cuestión de la razonabilidad y proporcionalidad de la carga que suponen los ajustes solicitados dada la singularidad de la deficiencia de movilidad que presentan las personas que realizan la diálisis peritoneal automática. Se discute, por lo tanto, si a las personas con enfermedad renal crónica que realizan la diálisis peritoneal automática se les estaría denegando un ajuste razonable si no se les permitiera embarcar la cicladora en la cabina del avión.

El Reglamento Europeo 1107/2006 comienza su exposición de motivos reconociendo que «las personas con discapacidad o movilidad reducida por motivos de discapacidad, edad o cualquier otro factor deben tener las mismas oportunidades de utilizar el transporte aéreo que los demás ciudadanos» pues «tienen el mismo derecho que todos los demás ciudadanos a la libertad de circulación, la libertad de elección y la no discriminación». Por lo tanto, no debe denegarse el transporte «alegando su discapacidad o movilidad reducida, salvo por motivos justificados por razones de seguridad y establecidos en la ley». En ese sentido, «las compañías aéreas, sus agentes y los operadores turísticos deben hacer todos los esfuerzos que sean razonables». Estos esfuerzos exigen «prestarles asistencia para satisfacer sus necesidades particulares tanto en los aeropuertos como a bordo de las aeronaves».

El artículo 1 del Reglamento Europeo 1107/2006 en su apartado 1 señala que su objetivo es establecer «las normas de protección y asistencia de personas con discapacidad o movilidad reducida en el transporte aéreo, tanto para protegerlas de la discriminación como para asegurar que reciban asistencia». En la definición de persona con discapacidad no se hace alusión alguna a un reconocimiento administrativo previo sino que se centra en la reducción de la movilidad por algún tipo de discapacidad, ya sea permanente o temporal (art. 2.a). De igual modo, en dicha definición se incluye a «todas las personas que son incapaces de usar el transporte aéreo sin la asistencia oportuna» (Guerrero, 2010, p. 143).

9. España. Tribunal Constitucional. Sentencia 10/2014, de 27 de enero de 2014. Fundamento Jurídico 5. Boletín Oficial del Estado, 25 de febrero de 2014, núm. 48, pp. 47-64. 
El artículo 3 prohíbe que las compañías aéreas, sus agentes o los operadores turísticos nieguen la reserva para un vuelo o el embarque alegando la discapacidad o movilidad reducida del pasajero si tiene un billete válido y una reserva. Las excepciones a esta prohibición se recogen en el artículo 4 pues cabe negar la reserva o el embarque cuando haya razones de seguridad o cuando las dimensiones de la aeronave lo imposibiliten físicamente. Adicionalmente, la compañía aérea puede exigir que una persona con discapacidad o movilidad reducida vaya acompañada por otra persona capaz de facilitarle la asistencia necesaria. En todo caso, las compañías aéreas deben proporcionar en formatos accesibles las normas de seguridad que apliquen al transporte de personas con discapacidad o movilidad reducida, «así como toda restricción del transporte de estas personas o del equipo de movilidad debida a las dimensiones de la aeronave». Cuando la compañía aérea, su agente o un operador turístico se acojan a las razones de seguridad o de dimensiones de la aeronave deberán notificarlo por escrito (art. 4.4).

Las razones de seguridad operarían como un límite al derecho a la libre circulación. Todo derecho tiene límites porque hay que proteger otros derechos o bienes constitucionalmente reconocidos ${ }^{10}$. El límite, en todo caso, debe estar establecido en una ley y ser necesario para la consecución de fines legítimos en una sociedad democrática, y su aplicación ha de ser razonada y razonable ${ }^{11}$. Así, la prohibición total del ejercicio de un derecho debe resultar absolutamente imprescindible pues no debe caber la posibilidad de adoptar ninguna otra medida menos drástica ${ }^{12}$. Esto significa que en la limitación de un derecho deben cumplirse los requisitos de idoneidad (la medida es susceptible de conseguir el objetivo propuesto), necesidad (no hay otra medida más moderada para la consecución de tal objetivo con igual eficacia) y proporcionalidad (la medida debe ser equilibrada por derivarse de ella más beneficios o ventajas para el interés general que perjuicios sobre otros bienes o valores en conflicto). Así, antes de prohibir el ejercicio del derecho, se debe ser especialmente diligente a la hora de buscar soluciones alternativas que garanticen su ejercicio ${ }^{13}$.

Las razones de seguridad que pueden utilizarse por las compañías aéreas son las incluidas en la Resolución de 20 de noviembre de 2018, de la Dirección General de Aviación Civil, por la que se publican las Instrucciones Técnicas para el Transporte Seguro de Mercancías Peligrosas por vía aérea (Documento OACI 9284/ AN/905). En dicha resolución se advierte que, en general, el transporte aéreo de mercancías peligrosas se encuentra regulado en el Reglamento (UE) 965/2012, de la Comisión, de 5 de octubre de 2012, por el que se establecen los requisitos técnicos y procedimientos administrativos en relación con las operaciones aéreas, en virtud del Reglamento (CE) 216/2008, del Parlamento Europeo y del Consejo, que ha incorporado al ordenamiento de la Unión Europea, por referencia dinámica, el anexo 18 del Convenio sobre Aviación Civil Internacional (Chicago, 1944) y las Instrucciones Técnicas para el transporte seguro de mercancías peligrosas por vía aérea. Por último, la disposición adicional segunda del Real Decreto 1180/2018, de 21 de septiembre, por el que se desarrolla el Reglamento del aire y disposiciones operativas comunes para los servicios y procedimientos de navegación aérea, remite al anexo 18 del Documento OACl y de las Instrucciones Técnicas para el transporte seguro de mercancías peligrosas por vía aérea, incorporadas por referencia del Reglamento (UE) 965/2012 para asegurar la uniformidad en las disposiciones aplicables a todos los sujetos que intervienen en el transporte aéreo de mercancías peligrosas y en todas las operaciones aéreas.

10. España. Tribunal Constitucional. Sentencia 2/1982, de 29 de enero de 1982. Fundamento Jurídico 5. Boletín Oficial del Estado, 26 de febrero de 1982, núm. 49, pp. 9-11.

11. España. Tribunal Constitucional. Sentencia 169/2001, de 16 de julio de 2001. Fundamento Jurídico 4. Boletín Oficial del Estado, 14 de agosto de 2001, núm. 194, pp. 71-84.

12. España. Tribunal Constitucional. Sentencia 66/1995, de 8 de mayo de 1995. Fundamento Jurídico 5. Boletín Oficial del Estado, 13 de junio de 1995, núm. 140, pp. 6-15.

13. España. Tribunal Constitucional. Sentencia 66/1995, de 8 de mayo de 1995. Fundamento Jurídico 5. Boletín Oficial del Estado, 13 de junio de 1995, núm. 140, pp. 6-15. 
Las especificaciones técnicas de las cicladoras determinan que no se les pueda considerar una mercancía que puede poner en peligro la seguridad de la aeronave e impida su transporte en la cabina de pasajeros pues tienen baterías, en especial las de litio, que están protegidas contra los cortocircuitos, sujetas por medio de tornillos al equipo, no contienen más de un gramo de litio, y están herméticamente selladas en un contenedor de acero inoxidable con una válvula de seguridad.

Si no cabe la aplicación de las razones de seguridad o de dimensión de la aeronave, y cumplido el requisito de notificación previa (art. 7), el transporte de los equipos de movilidad deberá hacerse sin cargo adicional (art. 10). En ese sentido, según señala el anexo II del Reglamento Europeo 1107/2006, las personas con discapacidad o movilidad reducida tienen derecho a transportar «además del equipo médico (...) hasta dos aparatos de equipos de movilidad (...) siempre que las limitaciones de espacio a bordo del avión no lo impidan, y sometido todo ello a la aplicación de la legislación pertinente en materia de mercancías peligrosas».

La cicladora es un equipo de movilidad pues el Reglamento Europeo 1107/2006 se aplica a personas con discapacidad que tienen un problema de movilidad por cualquier motivo, ya sea física, sensorial o intelectual (art. 2a). Es un concepto amplio de qué es un equipo de movilidad. De igual forma, el artículo 12, cuando regula las indemnizaciones por pérdida o daños, no limita el concepto equipo de movilidad a las sillas de ruedas, sino que incluye otros equipos de movilidad o dispositivos de asistencia.

\section{Discusión}

Las personas con discapacidad tienen reconocida la libertad de desplazamiento y circulación en el artículo 18 de la Convención, el artículo 12 del Pacto Internacional de Derechos Civiles y Políticos, el artículo 19 Constitución Española y el artículo 45 Carta de los Derechos Fundamentales de la Unión Europea. Esta libertad cobra una especial relevancia en las personas con discapacidad debido a las barreras a las que tradicionalmente han debido enfrentarse y porque es una pieza clave en el reconocimiento de un estatus jurídico pleno a todas las personas.

El derecho a la libre circulación tiene un contenido formado por un conjunto de libertades y facultades, es decir, de pretensiones jurídicas que no es sencillo delimitar o identificar (Goizueta, 2007, p. 114). El contenido de esta libertad se compondría por el derecho a elegir libremente su residencia; el derecho a circular por el territorio nacional; el derecho a entrar y salir libremente del territorio nacional. En esta reflexión interesa especialmente la libre facultad de ir y estar en el territorio nacional (Goizueta, 2007, p. 122) y en el territorio de la Unión Europea. Aunque todos los derechos y libertades pueden estar sujetos a limitaciones y condiciones derivadas del orden público, la seguridad o la salud pública, estas deben ser interpretadas de forma restrictiva, pues el ejercicio de la libre circulación y la libertad de desplazamiento deben promoverse y protegerse por parte de las administraciones públicas estatales y comunitarias, pues son claves para la promoción profesional y personal, acuñándose incluso el concepto de 'ciudadanía móvil' (Martín, 2014). La libertad de movimiento y la vida independiente están, por lo tanto, ligadas con el acceso al transporte, pues cada vez más las personas necesitan desplazarse para desarrollar diversas actividades.

A través del ejercicio de esta libertad de movimiento en igualdad de condiciones se trata de poner fin a la desventaja en el transporte (transportation disadvantage), que puede ser descrita como el conjunto de ba- 
rreras que descompensan las necesidades de movilidad y accesibilidad y las opciones de viaje disponibles, limitando el acceso a la participación en actividades esenciales fuera del hogar, entre las que estarían el empleo, la educación, las compras, el esparcimiento, la socialización y el cuidado médico (Combs et al., 2016). Las consecuencias de la desventaja en el transporte han sido profusamente estudiadas en diversos ámbitos (Lucas, 2012; Stanley et al., 2011) y se ha conectado con la pobreza intergeneracional (Chetty et al., 2016), las enfermedades crónicas (Wright, 2008) y la disminución de la calidad de vida (Kolodinsky et al, 2013).

La adopción de medidas de accesibilidad universal y de ajustes razonables lograría la inclusión social de las personas con discapacidad eliminando aquellas barreras (institucionales, normativas, actitudinales) a las que deben enfrentarse en el entorno construido. Entendemos por barrera todo aquel requisito o condición de acceso que impida o dificulte el ejercicio de un derecho en igualdad de condiciones (de Asís et al., 2007). Estas barreras deben removerse porque el entorno construido «está bajo el pleno control de la sociedad» (Comité sobre los Derechos de las Personas con Discapacidad, 2014, p. 2). Es el grupo social dominante quien configura la idea de normalidad, que constituye el patrón de acuerdo con el cual se configura el acceso a los diferentes ámbitos de la vida social. Esta idea o patrón de normalidad no es neutra, sino que viene impuesta por quienes responden «a los parámetros físicos y psíquicos del estereotipo culturalmente dominante» (Courtis, 2004, p. 7), obstaculizando la participación de aquellas personas que no encajan en el modelo estándar. Asumiendo esta premisa, las limitaciones que las personas encuentran para participar en la sociedad en igualdad de condiciones con los demás ya no se consideran naturales, sino que se conciben como el producto de una construcción social y de relaciones de poder (Cuenca, 2012, p. 34-35). Dicho de otro modo, estas restricciones se relacionan de manera directa con la presencia de barreras de diferente naturaleza que es preciso derrumbar, pues no es la persona la que tiene que adaptarse a un entorno normalizado sino que es el entorno (no solo físico, sino también intelectual, comunicacional y actitudinal) el que debe rediseñarse.

Sin un acceso universal al transporte público, las personas con discapacidad no pueden ejercer la libertad de circulación y no tendrían iguales oportunidades de participar en sus respectivas sociedades (Comité sobre los Derechos de las Personas con Discapacidad, 2014, p. 1). Si el transporte público es inaccesible, impedimos la creación de «una cadena irrestricta de desplazamiento de la persona de un espacio a otro» (Comité sobre los Derechos de las Personas con Discapacidad, 2014, p. 5) y con ello estamos ante un factor importante de marginación y exclusión que priva a las personas con discapacidad de ejercer algunos de sus derechos básicos, como el derecho a buscar empleo (Comité sobre los Derechos de las Personas con Discapacidad, 2014, p. 3). De ahí que la potestad que tienen las compañías aéreas de exigir que la persona con discapacidad esté acompañada por una tercera persona puede afectar al ejercicio de otros derechos (Biedma, 2012, p. 261).

Este derecho es especialmente importante para las personas con enfermedad renal crónica que hacen la diálisis peritoneal automática pues, aunque la enfermedad renal es una patología limitante en el aspecto laboral para muchas personas, la diálisis peritoneal es el tratamiento más compatible con el desempeño del trabajo. Así, el Grupo de Apoyo al Desarrollo de la Diálisis Peritoneal en España señala que «existen también diferencias en el porcentaje de ocupados en función del tratamiento sustitutivo renal, siendo el más elevado en los pacientes en diálisis peritoneal automática en domicilio (48\%) o en trasplante (39\%), con el menor porcentaje de pacientes activos en hemodiálisis (22\%)». Si tenemos en cuenta lo difícil que es incorporarse o continuar en el mercado laboral en el caso de las personas con enfermedad renal crónica (Julián-Mauro et al., 2012), una barrera que les impida viajar y movilizarse por el territorio nacional suma un motivo más 
de limitación de derechos y de discriminación para estas personas que optan por la diálisis peritoneal automática, sobre todo por el hecho de que eligen la diálisis peritoneal automática precisamente porque les permite seguir desarrollando su vida laboral. No toda persona con discapacidad viaja por motivos turísticos (Biedma, 2012, p. 247).

La respuesta a si, conforme a la Convención, la Ley general de derechos de las personas con discapacidad y de su inclusión social y el Reglamento Europeo 1107/2006, las personas con enfermedad renal crónica que realizan su tratamiento renal sustitutorio mediante diálisis peritoneal automática tienen derecho a que, dadas las condiciones de accesibilidad universal en el transporte aéreo, se realice un ajuste razonable para que la cicladora pueda ser embarcada como un equipo de movilidad en la cabina del avión, pues no es un objeto que ponga en peligro la seguridad de la aeronave; o si, por el contrario, están justificadas tanto la denegación del embarque por transportar la cicladora como equipaje de mano cuanto la obligación de facturar la cicladora para que sea transportada en la bodega del avión o la compra de un billete adicional para que viaje en el asiento contiguo; pasa por dos cuestiones que son claves: la primera es saber si se trata de un ajuste razonable que no supone una carga desproporcionada; la segunda es saber cómo se interpreta el concepto 'equipo de movilidad'.

Consideramos que el ajuste que se solicita es razonable porque es idóneo (la medida es susceptible de conseguir el objetivo propuesto), necesario (no hay otra medida más moderada para la consecución de tal objetivo con igual eficacia) y proporcional (la medida es equilibrada por derivarse de ella más beneficios o ventajas para el interés general que perjuicios sobre otros bienes o valores en conflicto). La razonabilidad de la medida se completa con el hecho de que no supone una carga desproporcionada para la compañía aérea al no imponer un coste que no pueda asumirse ya que bastaría con que la cicladora pudiera almacenarse en alguno de los compartimentos habilitados en la cabina de pasajeros de una aeronave. Sin la realización del ajuste, las personas con enfermedad renal crónica que realizan diálisis peritoneal automática no podrían disfrutar de su libertad de circulación y desplazamiento en igualdad de condiciones que el resto de las personas con movilidad reducida, produciéndose por lo tanto una discriminación. Las compañías aéreas deben evitar que se produzca tal discriminación adaptándose a las circunstancias de las personas con discapacidad, «facilitando las condiciones para que [estas] realicen un viaje cómodo y seguro» (Biedma, 2012, p. 248). Esto, en todo caso, supone imponer a las compañías aéreas una obligación derivada del servicio público prestado que sería proporcional (González, 2010, p. 246).

La cicladora, en segundo lugar, debe ser entendida como un equipo de movilidad pues sin ella la persona con discapacidad no puede circular ni desplazarse libremente, ya que es un producto sanitario que sustituye la función de un órgano. La cicladora para realizar la diálisis peritoneal automática es el equipo de movilidad del que dependen estas personas con enfermedad renal crónica para poder desplazarse libremente. No debería, pues, considerarse la cicladora como ‘equipaje’ que deba ser facturado (González, 2010, p. 265). La relación que se establece entre la persona con enfermedad renal crónica que realiza la diálisis peritoneal automática y la cicladora es de tal naturaleza que persona y máquina son inescindibles, inseparables. Existe una conexión entre persona y máquina que podría llegar a redefinir el propio concepto de ser humano.

Así, creemos que puede concluirse que los casos de denegación de embarque o de obligación de facturar la cicladora, siempre que la dimensión de la aeronave permita su transporte en cabina y dadas las especificaciones técnicas de las cicladoras, suponen una vulneración de la libertad de circulación reconocida en el artículo 18 Convención, en el artículo 19 Constitución Española y en el artículo 45 Carta de los Derechos Fundamentales de la Unión Europea, y de la prohibición de discriminación reconocida en el artículo 5 de la 
Convención, el artículo 14 de la Constitución Española y el artículo 21 de la Carta de los Derechos Fundamentales de la Unión Europea.

Las compañías aéreas, en estrecha colaboración con las asociaciones más representativas de los derechos de las personas con enfermedad renal crónica, deberían adoptar un protocolo de actuación, estableciendo los requisitos básicos de información y comunicación que se deberían cumplir y las adaptaciones que se deberían realizar, para garantizar que las personas con enfermedad renal crónica que realizan la diálisis peritoneal automática van a poder disfrutar de su libertad de circulación en igualdad de condiciones que el resto de las personas. Con ello se reduciría el margen de discrecionalidad de las compañías aéreas, que «casi siempre [alegan] razones de seguridad de dudosa fundamentación» (González, 2010, p. 260). 
de Asís, R. et al. (2007). Sobre la accesibilidad universal en el Derecho. Dykinson.

Biedma, J. M. (2012). El pasajero aéreo discapacitado y la normativa comunitaria. Especial referencia al turismo accesible. Anuario de la Facultad de Derecho de la Universidad de Alcalá, (5), pp. 245-272.

Chetty, R. et al. (2016). The effects of exposure to better neighborhoods on children: New evidence from the moving to opportunity experiment. American Economic Review, 106(4), pp. 855-902.

Combs, T. et al. (2016). Understanding the multiple dimensions of transportation disadvantage: the case of rural North Carolina. Case Studies on Transport Policy, 4(2), pp. 68-77.

Comité sobre los Derechos de las Personas con Discapacidad (2014). Observación general núm. 2 sobre el artículo 9: accesibilidad (CRPD/C/GC/2). Naciones Unidas.

Comité sobre los Derechos de las Personas con Discapacidad (2017). Observación general núm. 5 sobre el derecho a vivir de forma independiente y a ser incluido en la comunidad (CRPD/C/GC/5). Naciones Unidas.

Comité sobre los Derechos de las Personas con Discapacidad (2018). Observación general núm. 6 sobre la igualdad y la no discriminación (CRPD/C/GC/6). Naciones Unidas.

Courtis, C. (2004). Discapacidad e inclusión social: retos teóricos y desafíos prácticos. Jueces para la Democracia, (51), pp. 7-14.

Cuenca, P. (2012). Los derechos fundamentales de las personas con discapacidad. Universidad de Alcalá.

España. Constitución Española. Boletín Oficial del Estado, 29 de diciembre de 1978, núm. 311, pp. $29313-29424$.

España. Real Decreto Legislativo 1/2013, de 29 de noviembre, por el que se aprueba el Texto Refundido de la Ley General de derechos de las personas con discapacidad y de su inclusión social. Boletín Oficial del Estado, 3 de diciembre de 2013, núm. 289, pp. 95635-95673.

España. Real Decreto 1180/2018, de 21 de septiembre, por el que se desarrolla el Reglamento del aire y disposiciones operativas comunes para los servicios y procedimientos de navegación aérea y se modifican el Real Decreto 57/2002, de 18 de enero, por el que se aprueba el Reglamento de Circulación Aérea; el Real Decreto 862/2009, de 14 de mayo, por el que se aprueban las normas técnicas de diseño y operación de aeródromos de uso público y el Reglamento de certificación y verificación de aeropuertos y otros aeródromos de uso público; el Real Decreto 931/2010, de 23 de julio, por el que se regula el procedimiento de certificación de proveedores civiles de servicios de navegación aérea y su control normativo; y el Reglamento de la Circulación Aérea Operativa, aprobado por Real Decreto 601/2016, de 2 de diciembre. Boletín Oficial del Estado, 10 de noviembre de 2018, núm. 272, pp. 109405-109615.

España. Real Decreto 1971/1999, de 23 de diciembre, de procedimiento para el reconocimiento, declaración y calificación del grado de discapacidad. Boletín Oficial del Estado, 26 de enero de 2000, núm. 22, pp. 3317-3410.

España. Resolución de 20 de noviembre de 2018, de la Dirección General de Aviación Civil, por la que se publican las Instrucciones Técnicas para el Transporte Seguro de Mercancías Peligrosas por vía Aérea (Documento OACI 9284/AN/905). Boletín Oficial del Estado, 28 de diciembre de 2018, núm. 313, pp. 128241-129222.

González, A. M. (2010). Las obligaciones de servicio público en el transporte aéreo. lustel.

Goizueta, J. (2007). El derecho a la libre circulación y residencia en la Constitución Española. Tirant lo Blanch. 
Guerrero, M. J. (2010). Las últimas reformas en Derecho del transporte aéreo: avances y cuestiones pendientes en la protección de los pasajeros y los terceros. Revista Andaluza de Derecho del Turismo, (3), pp. 127-157.

Julián-Mauro, J. C. et al. (2012). La situación laboral del paciente con enfermedad renal crónica en función del tratamiento sustitutivo renal. Nefrología, 32(4), pp. 439-445.

Kolodinsky, J. M. et al. (2013). It is not how far you go, it is whether you can get there: modeling the effects of mobility on quality of life in rural New England. Journal of Transport Geography, 31, pp. 113-122.

Lucas, K. (2012). Transport and social exclusion: where are we now? Transport Policy, 20, pp.105-113.

Martín, M. (2014). Límites a la libre circulación de personas en la Unión Europea por razones de orden público, seguridad o salud pública en tiempos de crisis. Revista de Derecho Comunitario Europeo, (49), pp. 767-804.

Naciones Unidas. Pacto Internacional de Derechos Civiles y Políticos, hecho en Nueva York el 19 de diciembre de 1966. Ratificado por España el 13 de abril de 1977. Boletín Oficial del Estado, 30 de abril de 1977, núm. 103, pp. 9337-9343.

Naciones Unidas. Instrumento de Ratificación de la Convención sobre los derechos de las personas con discapacidad, hecho en Nueva York el 13 de diciembre de 2006. Ratificado por España el 23 de noviembre de 2007. Boletín Oficial del Estado, 21 de abril de 2008, núm. 96, pp. 20648-20659.

Sociedad Española de Nefrología (2018). La enfermedad renal crónica en España. Sociedad Española de Nefrología. https://senefro.org/contents/webstructure/comunicacion/SEN_dossier_Enfermedad_Renal_Cro.pdf.

Stanley, J. K. et al. (2011). Mobility, social exclusion and well-being: exploring the links. Transportation Research, 45(8), pp. 789-801.

Subdirección General de Calidad y Cohesión (2015). Documento marco sobre enfermedad renal crónica (ERC) dentro de la estrategia de abordaje a la cronicidad en el SNS. Ministerio de Sanidad, Servicios Sociales e Igualdad. https://www.mscbs.gob.es/organizacion/sns/planCalidadSNS/pdf/Enfermedad_Renal_Cronica_2015.pdf.

Unión Europea. Carta de los Derechos Fundamentales de la Unión Europea (2000/C 364/01). Diario Oficial de las Comunidades Europeas, 18 de diciembre de 2000, núm. 83, pp. 389-403.

Unión Europea. Reglamento (CE) n 1107/2006 del Parlamento Europeo y del Consejo, de 5 de julio de 2006, sobre los derechos de las personas con discapacidad o movilidad reducida en el transporte aéreo. Diario Oficial de la Unión Europea, 26 de julio de 2006, L 204, pp. 1-9.

Unión Europea. Reglamento (CE) n²16/2008 del Parlamento Europeo y del Consejo, de 20 de febrero de 2008, sobre normas comunes en el ámbito de la aviación civil y por el que se crea una Agencia Europea de Seguridad Aérea, y se deroga la Directiva 91/670/CEE del Consejo, el Reglamento (CE) n 1592/2002 y la Directiva 2004/36/CE. Diario Oficial de la Unión Europea, 19 de marzo de 2008, L 79, pp. 1-49.

Unión Europea. Reglamento (UE) n 965/2012 de la Comisión, de 5 de octubre de 2012, por el que se establecen requisitos técnicos y procedimientos administrativos en relación con las operaciones aéreas en virtud del Reglamento (CE) n²16/2008 del Parlamento Europeo y del Consejo. Diario Oficial de la Unión Europea, 25 de octubre de 2012, L 269, pp. 1-148.

Vega-Díaz, N. (2011). Aspectos relevantes de la diálisis peritoneal automática. Diálisis y Trasplante, 32(1), pp. 17-20.

Wright, D. (2008). No way to go: a review of the literature on transportation barriers in health care. World Transport Policy \& Practice, 14(3), pp. 7-23. 


\section{Anexo 1. Jurisprudencia}

Consejo de Europa. Sentencia del Tribunal Europeo de Derechos Humanos. Caso Çam contra Turquía, n. 51500/08, 23 de febrero de 2016.

España. Tribunal Constitucional. Sentencia 2/1982, de 29 de enero de 1982. Fundamento Jurídico 5. Boletín Oficial del Estado, 26 de febrero de 1982, núm. 49, pp. 9-11.

España. Tribunal Constitucional. Sentencia 269/1994, de 3 de octubre de 1994. Fundamento Jurídico 4. Boletín Oficial del Estado, 8 de noviembre de 1994, núm. 267, pp. 43-48.

España. Tribunal Constitucional. Sentencia 66/1995, de 8 de mayo de 1995. Fundamento Jurídico 5. Boletín Oficial del Estado, 13 de junio de 1995, núm. 140, pp. 6-15.

España. Tribunal Constitucional. Sentencia 169/2001, de 16 de julio de 2001. Fundamento Jurídico 4. Boletín Oficial del Estado, 14 de agosto de 2001, núm. 194, pp. 71-84.

España. Tribunal Constitucional. Sentencia 72/2005, 4 de abril de 2005. Fundamento Jurídico 5. Boletín Oficial del Estado, 10 de mayo de 2005, núm. 111, pp. 17-23.

España. Tribunal Constitucional. Sentencia 10/2014, de 27 de enero de 2014. Fundamento Jurídico 5. Boletín Oficial del Estado, 25 de febrero de 2014, núm. 48, pp. 47-64.

España. Tribunal Constitucional. Sentencia 3/2018, de 22 de enero de 2018. Fundamento Jurídico 4. Boletín Oficial del Estado, 21 de febrero de 2018, núm. 46, pp. 20410-20432.

Unión Europea. Sentencia del Tribunal de Justicia de la Unión Europea. Caso Daouidi C-354/13, 18 diciembre de 2014.

Unión Europea. Sentencia del Tribunal de Justicia de la Unión Europea. Caso Ring, C-335/11, 11 de abril de 2013. 